\title{
Leptin administration improves skeletal muscle insulin responsiveness in diet-induced insulin-resistant rats
}

\author{
BEN B. YASPELKIS III, ${ }^{1}$ JAMES R. DAVIS, ${ }^{2}$ MAZIYAR SABERI, ${ }^{1}$ TOBY L. SMITH, ${ }^{1}$ \\ REZA JAZAYERI,${ }^{1}$ MOHENISH SINGH,${ }^{1}$ VICTORIA FERNANDEZ, ${ }^{1}$ BEATRIZ TREVINO, ${ }^{1}$ \\ NARUMOL CHINOOKOSWONG,${ }^{3}$ JINLIN WANG,${ }^{3}$ ZHI QING SHI, ${ }^{3}$ AND NANCY LEVIN ${ }^{2}$ \\ ${ }^{1}$ Exercise Biochemistry Laboratory, Department of Kinesiology, California State \\ University Northridge, Northridge 91330-8287; and Departments of ${ }^{2}$ Neuroscience \\ and ${ }^{3}$ Pharmacology, Amgen Incorporated, Thousand Oaks, California 91320-1799
}

Received 10 April 2000; accepted in final form 20 September 2000

Yaspelkis, Ben B., III, James R. Davis, Maziyar Saberi, Toby L. Smith, Reza Jazayeri, Mohenish Singh, Victoria Fernandez, Beatriz Trevino, Narumol Chinookoswong, Jinlin Wang, Zhi Qing Shi, and Nancy Levin. Leptin administration improves skeletal muscle insulin responsiveness in diet-induced insulin-resistant rats. $A m \mathrm{~J}$ Physiol Endocrinol Metab 280: E130-E142, 2001.-In addition to suppressing appetite, leptin may also modulate insulin secretion and action. Leptin was administered here to insulin-resistant rats to determine its effects on secretagogue-stimulated insulin release, whole body glucose disposal, and insulin-stimulated skeletal muscle glucose uptake and transport. Male Wistar rats were fed either a normal (Con) or a high-fat (HF) diet for 3 or 6 mo. HF rats were then treated with either vehicle (HF), leptin (HF-Lep, 10 $\mathrm{mg} \cdot \mathrm{kg}^{-1} \cdot \mathrm{day}^{-1} \mathrm{sc}$ ), or food restriction (HF-FR) for 12-15 days. Glucose tolerance and skeletal muscle glucose uptake and transport were significantly impaired in HF compared with Con. Whole body glucose tolerance and rates of insulinstimulated skeletal muscle glucose uptake and transport in HF-Lep were similar to those of Con and greater than those of $\mathrm{HF}$ and HF-FR. The insulin secretory response to either glucose or tolbutamide (a pancreatic $\beta$-cell secretagogue) was not significantly diminished in HF-Lep. Total and plasma membrane skeletal muscle GLUT-4 protein concentrations were similar in Con and HF-Lep and greater than those in $\mathrm{HF}$ and HF-FR. The findings suggest that chronic leptin administration reversed a high-fat diet-induced insulin-resistant state, without compromising insulin secretion.

$o b$ gene product; high-fat diet; glucose tolerance; glucose uptake and transport; GLUT-4 protein

LEPTIN, THE PRODUCT of the $o b$ gene (62), has received a great deal of attention since its discovery in 1994, due to the ability of this $16-\mathrm{kDa}$ protein hormone to reduce visceral adipose deposition $(21,37)$. This biological activity is important from a public health perspective, as increases in visceral fat have been associated with "insulin resistance syndrome" or Syndrome X (39). Attenuation of insulin resistance will decrease the incidence of metabolic abnormalities such as hypertri-

Address for correspondence and reprint requests: B. B. Yaspelkis III, Dept. of Kinesiology, California State University Northridge, 1811 Nordhoff St., Northridge, CA 91330-8287 (E-mail: ben.yaspelkis@csun.edu). glyceridemia, reduced high-density lipoproteins, elevated apolipoprotein B levels, and hypertension. Furthermore, reduced visceral fat deposition may also prevent the development of non-insulin-dependent diabetes (17).

It is believed that leptin exerts its primary effect by acting on receptors in the hypothalamus, possibly via inhibition of neuropeptide Y release (47). However, leptin receptor isoforms are expressed in tissues other than the hypothalamus $(12,29,51)$, and insulin action (e.g., phosphatidylinositol 3-kinase activity, skeletal muscle glucose uptake and transport) is improved in these tissues after leptin treatment $(3,56,57,60)$. Improvements in insulin-stimulated glucose disposal after chronic leptin administration were initially demonstrated by Barzilai et al. (3) and Sivitz et al. (44). Barzilai et al. (3) reported that 8 days of leptin treatment increased whole body glucose uptake in SpragueDawley rats as assessed by the euglycemic clamp technique. In an extension to these findings, we (60) found that 14 days of leptin administration increased skeletal muscle glucose uptake and 3-O-methyl-D-glucose (3-MG) transport in hindlimbs of Sprague-Dawley rats. However, these observations $(3,44,60)$ were made in non-insulin-resistant animals. Although interventions that improve carbohydrate metabolism in normal animals also tend to be effective in insulin-resistant animals, it is unknown whether chronic leptin administration will improve an insulin-resistant state. Moreover, ex vivo pancreatic perfusion data suggest the possibility that leptin may have a detrimental effect on pancreatic secretagogue responsiveness (38).

Therefore, the aims of the present investigation were to evaluate the impact of chronic leptin administration in an insulin-resistant rodent model by assessing 1) the insulin secretory response to glucose and tolbutamide; 2) whole body glucose clearance; 3) insulin-stimulated skeletal muscle glucose uptake and 3-MG transport; and 4) if improvements in leptin-treated insulin-resistant skeletal muscle result from alterations in enzy-

The costs of publication of this article were defrayed in part by the payment of page charges. The article must therefore be hereby marked "advertisement" in accordance with 18 U.S.C. Section 1734 solely to indicate this fact. 
matic activity, glycogen concentration, and/or GLUT-4 protein concentration.

\section{METHODS}

Animals. All experimental procedures were approved by the Institutional Animal Care and Use Committees at Amgen (Thousand Oaks, CA) and California State University Northridge and conformed to the guidelines for use of laboratory animals published by the United States Department of Health and Human Resources.

Eight-week-old male Wistar rats (Harlan Sprague-Dawley, San Diego, CA) were housed two per cage in a temperature-, humidity-, and light-controlled room (lights on at 0630, lights off at 1830). Rats were provided water and one of two purified powdered diets ad libitum for 3 (experimental protocols 1 and 3) or 6 (experimental protocol 2) mo. The two diets were of either normal fat content (control diet, $17 \%$ fatderived calories, no. 112386; Dyets, Bethlehem, PA) or highfat content (high-fat diet, 59\% fat-derived calories, no. 112387; Dyets). Protein and carbohydrate contents of the diets were, respectively, 20 and $63 \%$ for control and 15 and $26 \%$ for the high-fat diet. The diets were identical with respect to vitamin and mineral content. A similar high-fat diet has previously been shown to induce skeletal muscle insulin resistance in rats $(48,49)$. Diets were stored at $4^{\circ} \mathrm{C}$, and fresh diet was provided to all rats two times a week.

At the end of the 3- or 6-mo dietary lead in, glucose tolerance of the rats was assessed after an intraperitoneal glucose challenge [intraperitoneal glucose tolerance test (IPGTT)]. Rats were fasted in the morning (food out at 0900) for $4 \mathrm{~h}$ before testing. At the onset of the IPGTT, rats (nonanesthetized) were introduced to plastic restrainers and were bled by producing a small incision in the tail vein and milking the tail ( $\sim 0.5 \mathrm{ml}$ blood). After this time 0 sample was collected, rats were injected with glucose $(2 \mathrm{~g} / \mathrm{kg} \mathrm{ip})$, and blood was collected from the tail ( $\sim 0.2 \mathrm{ml}$ blood) at 30 and 90 min after injection. Blood glucose levels were determined on all samples using a One-Touch Meter (Lifescan, San Carlos, CA). Glucose-intolerant rats were defined as those that displayed a blood glucose value at 90 min that was $80 \%$ or more of the value at $30 \mathrm{~min}$. With the use of this criterion, between 25 and $35 \%$ of the high fat-fed rats were found to be glucose intolerant. Serum insulin levels in the time 0 samples were determined by RIA (Linco Research, St. Louis, MO). Serum leptin levels in the time 0 sample were determined by enzyme-linked immunosorbent assay (59).

Glucose-intolerant high-fat diet-fed rats were then assigned to one of three treatment groups. Treatments were given for 12-15 days, during which time rats continued to consume the high-fat diet. Two treatment groups [high-fat-fed rats (HF) and high-fat-fed food-restricted rats (HF-FR)] received twice daily subcutaneous injections of vehicle (PBS). The third treatment group [high-fat-fed leptin-treated rats (HF-Lep)] was injected subcutaneously twice daily with recombinant murine leptin (5 $\mathrm{mg} \cdot \mathrm{kg}^{-1} \cdot$ injection $^{-1}, 10 \mathrm{mg} \cdot \mathrm{kg}^{-1} \cdot$ day $^{-1}$ total dose; Amgen). The HF and HF-Lep groups consumed the high-fat diet ad libitum, whereas the food-restricted (HF-FR) group was provided $15 \mathrm{~g} /$ day of the high-fat diet for treatment days 1-6 and 13 g/day of high-fat diet from days 7-15 of the experimental period. These food intake values were based on observations of food intake in the HF-Lep rats (Davis and Levin, unpublished observations). A fourth treatment group consisted of rats that had been fed the control diet (Con) and demonstrated normal glucose tolerance. Con rats continued to consume the control diet ad libitum during the treatment periods and were injected two times daily with PBS subcutaneously. Injections were administered at 0800 and 1800 using a volume of $\sim 0.25 \mathrm{ml}$.

Experimental protocol 1. For this protocol, rats were maintained on either the control or the high-fat diet for $3 \mathrm{mo}$ before selection of glucose-intolerant rats. Glucose-intolerant, high-fat-fed rats were divided into treatment groups ( $n=10-12$ /group) and received either vehicle (HF) or leptin (HF-Lep) for 15 days. An additional group of glucose-intolerant, high-fat-fed rats was treated with vehicle and were food restricted (HF-FR) following the predetermined schedule described above that mimicked the intake of the HF-Lep rats. A group of rats fed the control (Con) diet $(n=10)$ and injected with vehicle was also studied. Treatments were initiated immediately after the 3-mo dietary lead in. On day 7 of the 15-day treatment period, rats were anesthetized with pentobarbital sodium and implanted with carotid artery and jugular vein cannulas. Cannulas were exteriorized in the midscapular region, and patency was maintained by daily flushing with a heparin-saline solution. The insulin secretory response to an intravenous glucose challenge $(1 \mathrm{~g} / \mathrm{kg})$ was assessed over a 60-min period on treatment day 12 in conscious rats. The insulin secretory response to an intravenous tolbutamide injection $(0.1 \mathrm{~g} / \mathrm{kg})$ was assessed over a 60 -min period on treatment day 14 or 15 in conscious rats. Tolbutamide was employed to assess pancreatic insulin secretory capacity without the confound of glucose-sensing ability. Tolbutamide binds to the sulfonylurea receptor in the $\beta$-cells of the pancreas, blocking the ATP-dependent potassium $\left(\mathrm{K}_{\mathrm{ATP}}\right)$ channels and resulting in insulin secretion. For these tests, rats were fasted in the morning (food removed at 0900) for $4 \mathrm{~h}$ before and during testing. Fifteen minutes before testing, the cannulas were extended with additional tubing (PE-50) to allow for dosing and sampling without disturbing the rat, and a prestudy blood sample $(\sim 0.5 \mathrm{ml})$ was drawn from the arterial cannulas. At time 0 , a small $(<0.1 \mathrm{ml})$ blood sample was drawn from the arterial cannulas, and then the test substance was administered through the venous cannulas. Small $(<0.1 \mathrm{ml})$ blood samples were collected from the arterial cannulas after glucose or tolbutamide dosing at 1.5, 3 , $4.5,6,7.5,10,12.5,15,17.5,20,25,30,40,50$, and $60 \mathrm{~min}$. Serum from these samples was separated by centrifugation and stored at $-20^{\circ} \mathrm{C}$ until subsequent determination of glucose (by the glucose oxidase method) and insulin (by RIA) levels.

Experimental protocol 2. For this protocol, rats were maintained on the high-fat diet for 6 mo before selection of glucose-intolerant rats. Treatment groups included HF-Lep and HF-FR, and treatments were initiated immediately after the 6-mo dietary lead in. Glucose-intolerant, high-fat-fed rats were divided into treatment groups ( $n=5$-6/group) and received either vehicle or leptin (HF-Lep) for 12 days. The vehicle-treated rats were food restricted (HF-FR) following the predetermined schedule described above that mimicked the intake of the HF-Lep rats. As in experiment protocol 1, rats were outfitted with carotid artery and jugular vein cannulas on day 7 of treatment, and cannula patency was ensured by daily flushing with heparin-saline.

On treatment day 12, rats were fasted in the morning for $4 \mathrm{~h}$ before initiation of the hyperinsulinemic-euglycemic clamp study, as previously described by Shi et al. (43). The jugular vein cannulas were used for infusion of insulin and glucose via serial T-shaped needle connectors. Constant insulin infusion $\left(4 \mathrm{mU} \cdot \mathrm{kg}^{-1} \cdot \mathrm{min}^{-1}\right)$ began at $0 \mathrm{~min}$, and an exogenous glucose infusion (30\%) was given at variable rates to achieve and maintain stable euglycemia. Carotid arterial samples were taken at timed intervals, and plasma was collected in ice-chilled microtubes containing EGTA/aproti- 
nin. Plasma glucose levels were determined using a Glucose Analyzer II (Beckman Instruments, Fullerton, CA). The packed blood cells were resuspended in heparinized saline and reinfused.

Experimental protocol 3. For this protocol, rats were maintained on either the control or the high-fat diet for $3 \mathrm{mo}$ before selection of glucose-intolerant rats. Approximately $2-3$ wk after the dietary lead in, animals were divided among two perfusion groups. Perfusion group 1 consisted Con $(n=$ $7)$, HF $(n=7)$, HF-FR $(n=7)$, and HF-Lep $(n=7)$ animals. Perfusion group 2 consisted of Con $(n=8), \mathrm{HF}$ $(n=8)$, and HF-Lep $(n=8)$ animals. Animals were treated with either leptin or vehicle for 12 days. After the 12-day treatment period, animals were anesthetized with an intraperitoneal injection of pentobarbital sodium $(6.5 \mathrm{mg} / 100 \mathrm{~g}$ body wt) and surgically prepared for hindlimb perfusion as described previously by Ruderman et al. (41) and modified by Ivy et al. (25). After the surgical preparation, the soleus (Sol), plantaris (Plant), and red (RG) and white (WG) portions of the gastrocnemius and quadricep were excised from the left leg, clamp-frozen in liquid nitrogen, and stored at $-80^{\circ} \mathrm{C}$ until analysis. Total GLUT-4 protein concentration, enzymatic analysis, and muscle glycogen content were assessed in the Sol, Plant, RG, and WG from perfusion group 1. Total GLUT-4 protein concentration and intramuscular triglyceride content was assessed in the quadriceps of perfusion group 2 . The right iliac artery was then catheterized to the tip of the femoral artery to limit perfusate flow to the right hindlimb. Catheterization of the lower abdominal vena cava to the tip of the iliac vein permitted the collection of effluent perfusate. Immediately after catheterization of the vessels, rats were killed via an intracardiac injection of pentobarbital sodium as the hindlimbs were being washed out with $10 \mathrm{ml}$ of Krebs-Heinseleit buffer (KHB). The catheters were then placed in line with a nonrecirculating perfusion system, and the hindlimb was allowed to stabilize during a 5-min washout period. The perfusate was gassed continuously with a mixture of $95 \% \mathrm{O}_{2}-5 \% \mathrm{CO}_{2}$ and was warmed to $37^{\circ} \mathrm{C}$. Perfusate flow rate was set at $5 \mathrm{ml} / \mathrm{min}$ during the 5 -min stabilization and the subsequent perfusion, during which the rates of muscle glucose uptake and glucose transport were determined.

Perfusions were carried out in the presence of a submaximal insulin concentration $(500 \mu \mathrm{U} / \mathrm{ml})$ for all experimental groups. The basic perfusate medium consisted of $30 \%$ washed time-expired human erythrocytes (HemaCare, Van Nuys, CA), KHB (pH 7.4), 4\% dialyzed BSA (Fraction V; Fisher Scientific, Fair Lawn, NJ), and $0.2 \mathrm{mM}$ pyruvate. Over the first $20 \mathrm{~min}, 8 \mathrm{mM}$ glucose was present in the perfusate, and it was during this period that glucose uptake was measured across the hindlimb. Subsequent to the determination of glucose uptake, the hindlimb was washed out with glucosefree perfusate for $1 \mathrm{~min}$ in preparation for the measurement of glucose transport. Glucose transport was measured over an 8-min period using an $8 \mathrm{mM}$ concentration of the nonmetabolizable glucose analog $3-\mathrm{MG}\left(32 \mu \mathrm{Ci} 3-\left[{ }^{3} \mathrm{H}\right] \mathrm{MG} / \mathrm{mmol}\right)$ and $2 \mathrm{mM}$ mannitol $\left(60 \mu \mathrm{Ci}\right.$ - $\left.\left[1-{ }^{14} \mathrm{C}\right] \mathrm{mannitol} / \mathrm{mmol}\right)$. Immediately at the end of the transport period, the Sol, Plant, RG, and WG were excised from the right leg, blotted on gauze dampened in cold KHB, and clamp-frozen in tongs cooled in liquid $\mathrm{N}_{2}$. The muscles were stored at $-80^{\circ} \mathrm{C}$ until analyzed. Sol, Plant, RG, and WG from perfusion group 1 were used to determine rates of insulin-stimulated 3-MG transport, whereas the quadriceps from perfusion group 2 were used to assess insulin-stimulated plasma membrane GLUT-4 protein concentration.
Glucose uptake was determined over a 20-min nonrecirculating perfusion by collecting arterial perfusate samples before perfusion and collecting the total venous effluent. Wellmixed aliquots of the arterial perfusate and venous effluent were analyzed for glucose concentration by a glucose oxidase method on a model 2300 STAT Plus glucose analyzer (Yellow Springs Instruments, Yellow Springs, OH). Muscle glucose uptake, expressed in micromoles per gram per hour, was calculated from the arteriovenous difference, the perfusate flow rate, and the weight of the muscle perfused. The weight of the perfused muscle was determined by dissection of the rat hindlimb (42).

Muscle samples were weighed, homogenized in $1 \mathrm{ml}$ of $10 \%$ TCA at $4^{\circ} \mathrm{C}$, and centrifuged in a microcentrifuge (Fisher Scientific, Houston, TX) for 10 min. Duplicate $300-\mu l$ samples of the supernatant were transferred to $7-\mathrm{ml}$ scintillation vials containing $6 \mathrm{ml}$ of Bio-Safe II scintillation counting cocktail (Research Products International, Mount Prospect, IL) and vortexed. For determination of perfusate specific activity, 200 $\mu \mathrm{l}$ of the arterial perfusate were added to $800 \mu \mathrm{l}$ of $10 \%$ TCA and treated the same as the muscle homogenates. The samples were counted for radioactivity in a LS 1801 liquid scintillation spectrophotometer (Beckman Instruments, Fullerton, CA) set for simultaneous counting of ${ }^{14} \mathrm{C} /{ }^{3} \mathrm{H}$. The accumulation of intracellular $3-\left[{ }^{3} \mathrm{H}\right] \mathrm{MG}$, which is indicative of muscle glucose transport, was calculated by subtracting the concentration of $3-\left[{ }^{3} \mathrm{H}\right] \mathrm{MG}$ in the extracellular space from the total muscle $3-\left[{ }^{3} \mathrm{H}\right] \mathrm{MG}$ concentration. The $3-\left[{ }^{3} \mathrm{H}\right] \mathrm{MG}$ in the extracellular space was quantified by measuring the concentration of $\left[{ }^{14} \mathrm{C}\right]$ mannitol in the homogenate.

Total skeletal muscle GLUT-4 glucose transporter content was determined by Western blotting as described previously (61). Briefly, portions of the freeze-clamped muscles from the left hindlimb were weighed frozen and then homogenized in Hepes-EDTA-sucrose (HES) buffer. The protein concentration of the homogenate was determined by the Bradford (6) method. A 100- $\mu$ l sample of the tissue homogenate was diluted 1:1 with Laemmli (31) sample buffer. An aliquot of the diluted homogenate sample containing $75 \mu \mathrm{g}$ of protein was subjected to SDS-PAGE run under reducing conditions on a $12.5 \%$ resolving gel on a Mini-Protean II dual slab cell (BioRad, Richmond, CA). Resolved proteins were transferred to polyvinylidene difluoride (PVDF) sheets (Bio-Rad, Richmond, CA) by the method of Towbin et al. (53) using a Bio-Rad wet transfer unit. The membranes were incubated with an affinity-purified polyclonal GLUT-4 antibody (donated by Dr. Samuel W. Cushman, National Institute of Diabetes and Digestive and Kidney Diseases, Bethesda, MD) followed by incubation with horseradish peroxidase-labeled protein A (Amersham Life Science, Arlington Heights, IL). Antibody binding was visualized using enhanced chemiluminescence autoradiography in accordance with the manufacturer's instructions (Amersham Life Science). Labeled bands were quantified by capturing images of the autoradiographs in a Macintosh G3 computer. The captured images of the autoradiographs were produced by an image scanner (ScanJet 4C; Hewlett Packard, Boise, ID) equipped with a transparency module. The captured images were digitized and imported into the public domain NIH image program (developed at the United States National Institutes of Health and available on the Internet at http://rsb.info.nih.gov/nih-image/). The density of the labeled bands was calculated, corrected for background activity, and expressed as a percentage of a standard (30 $\mu \mathrm{g}$ of heart homogenate protein) run on each gel.

Plasma membrane fractions were prepared from portions of the perfused quadricep according to the procedure of Turcotte et al. (54). Briefly, a portion of the quadriceps was 
Table 1. Baseline prestudy body mass and hormone levels

\begin{tabular}{|c|c|c|c|c|c|}
\hline & \multicolumn{2}{|c|}{ Experimental Protocol 1} & \multirow{2}{*}{$\begin{array}{c}\begin{array}{c}\text { Experimental } \\
\text { Protocol } 2\end{array} \\
\mathrm{HF}(n=13)\end{array}$} & \multicolumn{2}{|c|}{ Experimental Protocol 3} \\
\hline & $\begin{array}{c}\text { Con } \\
(n=10)\end{array}$ & $\begin{array}{c}\mathrm{HF} \\
(n=35)\end{array}$ & & $\begin{array}{c}\text { Con } \\
(n=15)\end{array}$ & $\begin{array}{c}\mathrm{HF} \\
(n=37)\end{array}$ \\
\hline \multicolumn{6}{|l|}{ Body mass, g } \\
\hline 2 Months old & $222 \pm 4$ & $224 \pm 2$ & $243 \pm 4$ & $255 \pm 12$ & $267 \pm 8$ \\
\hline After dietary lead in & $587 \pm 18$ & $644 \pm 10^{*}$ & $769 \pm 23$ & $598 \pm 15$ & $713 \pm 17^{*}$ \\
\hline Fasting serum insulin, ng/ml & $3.5 \pm 0.3$ & $2.9 \pm 0.2$ & $3.3 \pm 0.4$ & $3.7 \pm 0.8$ & $4.0 \pm 0.3$ \\
\hline
\end{tabular}

Values are means $\pm \mathrm{SE} ; n$, no. of animals. Con, control diet; HF, high-fat diet. After dietary lead in, animals were 5 mo old in protocols 1 and 3 and 8 mo old in protocol 2. *Significantly different from Con within experimental protocol $(P<0.05)$. ND, not determined.

minced, diluted $1: 7$ in a $10 \mathrm{mM}$ Tris- $15 \%$ sucrose solution $(\mathrm{pH}$ 7.5) that contained $0.1 \mathrm{mmol} / \mathrm{l}$ phenylmethylsulfonyl fluoride, $10 \mathrm{mmol} / \mathrm{l} \mathrm{EGTA}$, and $10 \mathrm{mg} / \mathrm{ml}$ trypsin inhibitor, and homogenized with a PT 2100 Polytron homogenizer (Kinematica, Littau/Luzern, Switzerland). The homogenate was filtered and centrifuged at 100,000 $\mathrm{g}$ for $1 \mathrm{~h}$ using a Sorvall T-1250 rotor (Kendro Laboratory Products, Newton, CT). The pellet was resuspended in $10 \mathrm{mM}$ Tris-15\% sucrose buffer, and a small aliquot from this resuspension was collected and retained for analysis and will be referred to as the crude homogenate. The remaining crude homogenate suspension was layered on continuous sucrose gradients $(35-70 \%)$ and centrifuged at $120,000 \mathrm{~g}$ for $2 \mathrm{~h}$ in a Sorvall Surespin 630/36 rotor. The plasma membrane layer was collected, washed in $10 \mathrm{mM}$ Tris buffer, and centrifuged for $1 \mathrm{~h}$ at 100,000 $\mathrm{g}$ in a Sorvall T-1250 rotor. The final plasma membrane pellet was resuspended in a small volume of $10 \mathrm{mM}$ Tris buffer $(200 \mu \mathrm{l} / \mathrm{g}$ of original tissue), frozen in liquid nitrogen, and stored at $-80^{\circ} \mathrm{C}$ until analyzed. To assess the purity of the plasma membrane fractions, protein content of the plasma membrane (6) and activity of the plasma membrane marker enzyme 5'-nucleotidase was measured (52) and compared with activity in the crude homogenate fraction. Aliquots of the plasma membrane $(70 \mu \mathrm{g}$ of protein) were treated with Laemmli sample buffer and subjected to SDS-PAGE run under reducing conditions on a $10 \%$ resolving gel. Resolved proteins were transferred to PVDF by the method of Towbin et al. (53) using a Bio-Rad semidry transfer unit, and GLUT-4 protein content of the plasma membrane was determined by Western blotting as described above.

Aliquots of muscle samples that were homogenized 1:20 in HES buffer were used for enzymatic analysis. Hexokinase, an enzyme required for glucose metabolism, was measured as described by Uyeda and Racker (55). Citrate synthase, a marker of the tricarboxylic acid cycle, was measured spectrophotometrically (45) after dilution of the initial homogenate $1: 10$ in $1 \mathrm{M}$ Tris $\cdot \mathrm{HCl}+0.4 \%$ Triton $\mathrm{X}(\mathrm{pH} 8.1)$. For determination of $\beta$-hydroxyacetyl-CoA dehydrogenase ( $\beta$-OAC), a marker of $\beta$-oxidation, homogenates from the WG were diluted 1:5, whereas homogenates from the Sol, Plant, and RG were diluted 1:20 in $167 \mathrm{mM}$ triethanolamine- $\mathrm{HCl}$ buffer, $\mathrm{pH}$ 7.0. $\beta$-OAC activity was determined spectrophotometrically according to the procedure described by Bass et al. (4).

Muscle glycogen concentration was determined in the Sol, Plant, RG, and WG using a modification of the Passonneau and Lauderdale (36) procedure. Approximately $50 \mathrm{mg}$ of muscle were dissolved in $1 \mathrm{ml}$ of $1 \mathrm{~N} \mathrm{KOH}$ at $70^{\circ} \mathrm{C}$ for $30 \mathrm{~min}$. One hundred microliters of the dissolved homogenate were removed and neutralized with $250 \mu \mathrm{l}$ of $0.3 \mathrm{M}$ sodium acetate buffer ( $\mathrm{pH} 4.8$ ) and $10 \mu \mathrm{l}$ of $50 \%$ glacial acetic acid. The homogenate was then incubated for $2 \mathrm{~h}$ at $100^{\circ} \mathrm{C}$ after the addition of $200 \mu \mathrm{l}$ of $2 \mathrm{~N} \mathrm{HCl}$. After the incubation, the reaction mixture was neutralized with $2 \mathrm{~N} \mathrm{NaOH}$. Samples were then analyzed by measuring glucosyl units by the Trinder reaction (Sigma, St. Louis, MO). A portion of the quadricep was homogenized 1:20 in $25 \mathrm{mM} \mathrm{KF} / 20 \mathrm{mM}$ EDTA buffer, $\mathrm{pH}$ 7.0, and subjected to lipid extraction as described by Burton et al. (9). Total triglyceride content of the lipid extract was determined using a commercially available kit (Infinity Triglycerides; Sigma-Aldrich, St. Louis, MO).

Statistical analysis. A one-way ANOVA was used on all variables in experimental protocols 1 and 3 to determine whether significant differences existed between the Con, HF-Lep, HF, and HF-FR groups. When a significant $F$-ratio was obtained, a Fisher's protected least significant difference post hoc test was employed to identify statistically significant differences $(P<0.05)$ among the means. Glucose infusion data in experimental protocol 2 were analyzed using a twoway ANOVA (treatment $\times$ time) for repeated measures.

\section{RESULTS}

Effects of high-fat diet consumption. Rats that had consumed the high-fat diet ad libitum for $12 \mathrm{wk}$ (experimental protocols 1 and 3) gained significantly more weight and had higher fasting serum leptin concentrations than did rats that consumed the control diet for the same duration (Table 1). At the end of the $12 \mathrm{wk}$ of dietary manipulation, an IPGTT was performed to determine which rats had developed glucose intolerance as a consequence of consumption of the high-fat diet. Results from the IPGTT of rats used in experimental protocol 3 are depicted in Fig. 1. Similar findings were observed in the two independent cohorts of rats used in experimental protocols 1 and 2 (data not shown). In one of the three cohorts (Fig. 1), fasting blood glucose levels immediately before the intraperitoneal glucose injection were slightly but significantly greater in the high-fat-fed rats compared with the controls.

Experimental protocol 1. On treatment day 12, immediately before intravenous glucose tolerance testing, a blood sample was drawn to determine fasting hormone and clinical chemistry of the rats. As expected, serum leptin levels (sampled 4-6 $\mathrm{h}$ after the morning injection of leptin) were significantly increased in the HFLep group compared with all other groups (Table 2). Although HF-Lep and HF-FR rats had consumed significantly less food than HF rats over the 12-day treatment period, the body weights of these animals were not significantly less than the HF rats fed ad libitum 
Fig. 1. Blood glucose levels during intraperitoneal glucose tolerance test (IPGTT) in rats fed either a control diet (Con, $n=$ 8) or a high-fat diet (HF, $n=24$ ) for 12 wk before testing. Values are means $\pm \mathrm{SE}$. * Significantly different from Con $(P<$ $0.05)$.

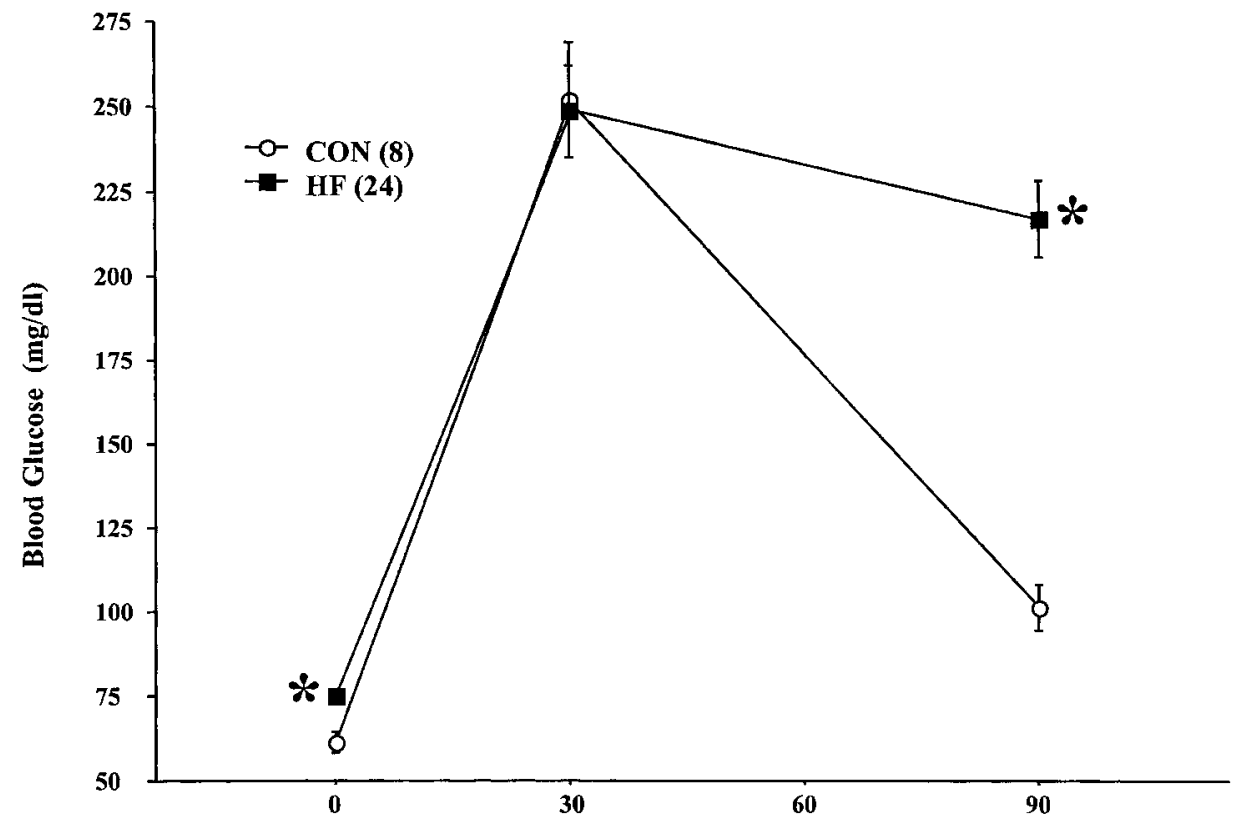

Time after IP Glucose Challenge (min)
(Table 2). Serum thyroxine levels were also significantly and similarly reduced in the HF-Lep and HF-FR groups relative to the HF group. Fasting $\beta$-hydroxybutyrate levels in the HF-Lep group were significantly higher than all other groups. The significant reduction in nonesterified fatty acid levels in the HF group, relative to the Con group, was not observed in HF-FR or HF-Lep rats.

Intravenous glucose tolerance tests were performed on day 12 of the treatment period. The areas under the curve (AUCs) for glucose, calculated from 0 to $25 \mathrm{~min}$ (intravenous glucose administration at $0 \mathrm{~min}$ ), are shown in Fig. 2A. The glucose AUC in HF rats was significantly increased when compared with Con rats $(P<0.05)$. This increase was reversed by leptin treatment in the HF-Lep rats to an AUC similar to that observed in the Con rats and significantly lower than the HF rats $(P<0.01)$. The glucose AUC for HF-FR rats was not different from that observed for HF rats.

AUCs for insulin, calculated from 0 to 25 min (intravenous glucose administration at $0 \mathrm{~min}$ ), are shown in Fig. $2 B$. The insulin secretory response to the intravenous glucose challenge was not significantly different across the four treatments groups. There was a tendency for the insulin AUC to be lowest in the HF-Lep group. Importantly, no worsening of glucose tolerance was observed in the HF-Lep rats, as they displayed glucose AUCs significantly lower than those observed in HF rats (Fig. 2A). Leptin treatment therefore did not significantly affect insulin secretory output and was accompanied by improved glucose tolerance in the insulin-resistant model. Further observations of the ef-

Table 2. Body mass, food intake, serum hormones, and clinical chemistry after 12 days of treatment/feeding regimen

\begin{tabular}{|c|c|c|c|c|}
\hline & $\begin{array}{c}\text { Con } \\
(n=10)\end{array}$ & $\begin{array}{l}\text { HF-Lep } \\
(n=12)\end{array}$ & $\begin{array}{c}\mathrm{HF} \\
(n=11)\end{array}$ & $\begin{array}{c}\text { HF-FR } \\
(n=12)\end{array}$ \\
\hline Body mass, $\mathrm{g}$ & $584 \pm 20$ & $616 \pm 16$ & $645 \pm 20$ & $610 \pm 20$ \\
\hline Cumulative food intake, $\mathrm{g}$ & $215.6 \pm 7.4$ & $137.5 \pm 8.0^{* \dagger}$ & $165.2 \pm 8.5^{*}$ & $143.2 \pm 4.8^{* \dagger}$ \\
\hline Insulin, ng/ml & $2.2 \pm 0.2$ & $1.4 \pm 0.3$ & $1.8 \pm 0.2$ & $1.7 \pm 0.2$ \\
\hline Leptin, ng/ml & $6.3 \pm 0.9$ & $193.5 \pm 42.2 \dagger$ & $7.5 \pm 1.2$ & $5.7 \pm 0.9$ \\
\hline Glucose, $\mathrm{mg} / \mathrm{dl}$ & $157 \pm 6$ & $144 \pm 3$ & $152 \pm 7$ & $148 \pm 5$ \\
\hline Cholesterol, mg/dl & $94 \pm 4$ & $79 \pm 3$ & $83 \pm 4$ & $87 \pm 12$ \\
\hline Triglycerides, mg/dl & $127 \pm 14$ & $86 \pm 12$ & $107 \pm 15$ & $132 \pm 33$ \\
\hline Total protein, g/dl & $6.5 \pm 0.1$ & $6.3 \pm 0.1$ & $6.4 \pm 0.2$ & $6.5 \pm 0.1$ \\
\hline Albumin, g/dl & $4.0 \pm 0.1$ & $3.9 \pm 0.1$ & $4.2 \pm 0.1$ & $4.0 \pm 0.1$ \\
\hline Alanine aminotransferase, U/l & $20 \pm 3$ & $31 \pm 5$ & $34 \pm 4$ & $28 \pm 5$ \\
\hline Thyroxine, $\mu \mathrm{g} / \mathrm{dl}$ & $4.3 \pm 0.5$ & $3.4 \pm 0.5 \dagger$ & $4.9 \pm 0.3$ & $3.3 \pm 0.3 \dagger$ \\
\hline$\beta$-Hydroxybutyrate, mg/dl & $2.2 \pm 0.4$ & $6.4 \pm 0.6^{* \dagger}$ & $3.6 \pm 0.5$ & $3.8 \pm 0.6$ \\
\hline Nonesterified fatty acids, meq/l & $4.1 \pm 0.4$ & $2.8 \pm 0.3$ & $2.4 \pm 0.4^{*}$ & $3.2 \pm 0.4$ \\
\hline
\end{tabular}

Values are means $\pm \mathrm{SE} ; n$, no. of animals. HF-Lep, high-fat diet and leptin treated; HF-FR, high-fat diet and food restricted. * Significantly different from Con $(P<0.05)$. $†$ Significantly different from $\mathrm{HF}(P<0.05)$. 

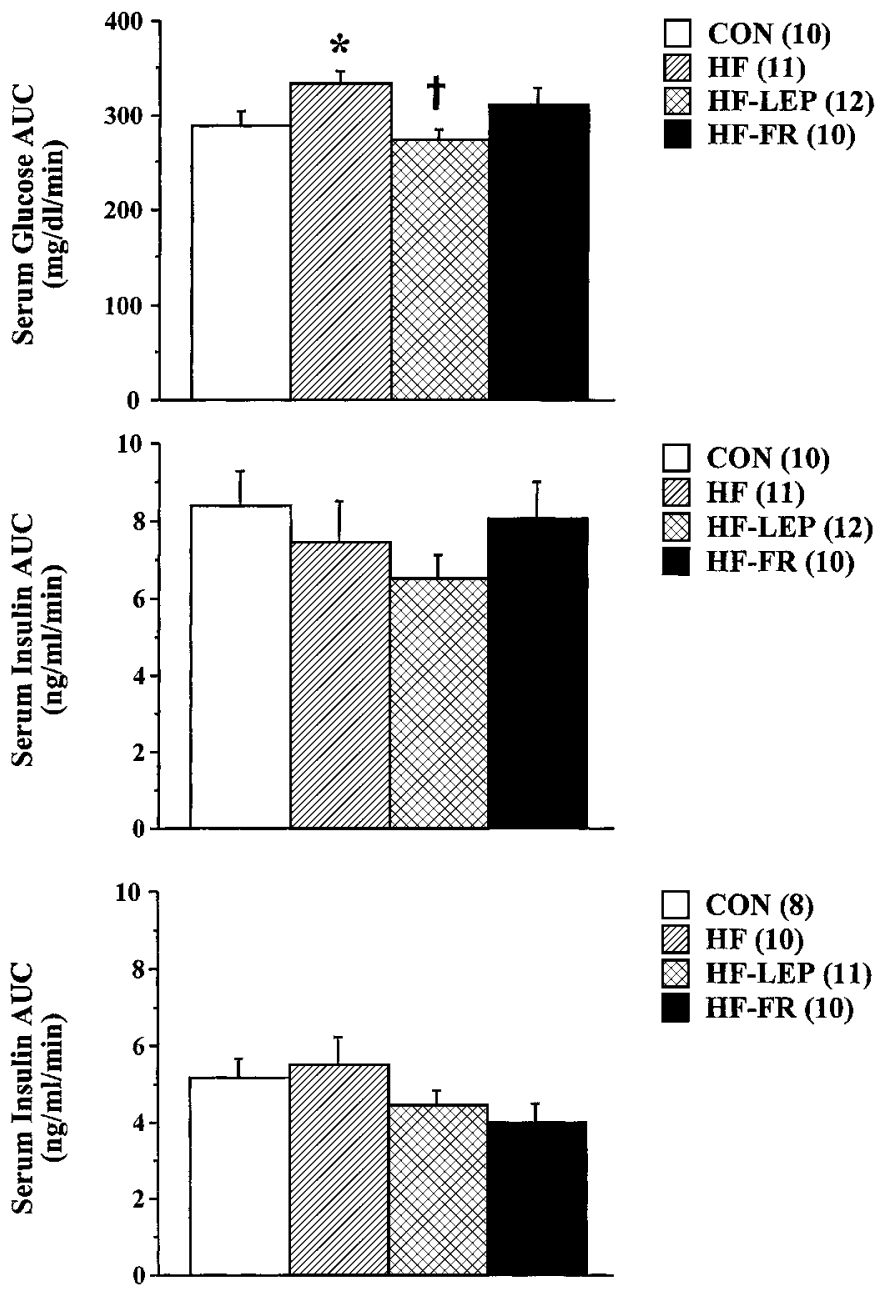

Fig. 2. Serum glucose and insulin areas under the curve (AUCs) after intravenous injection of glucose $(A$ and $B ; 0-25 \mathrm{~min})$ or tolbutamide $(C ; 0-60 \mathrm{~min})$ in Con $(n=10)$, HF $(n=11)$, high-fat diet and leptin-treated (HF-Lep, $n=12$ ), or high-fat diet and foodrestricted (HF-FR, $n=10)$ rats. Values are means \pm SE. *Significantly different from $\operatorname{Con}(P<0.05)$. $\dagger$ Significantly different from $\mathrm{HF}(P<0.05)$

fects of chronic leptin administration on glucose homeostasis were pursued in experimental protocols 2 and 3.

To better characterize the insulin secretory capacity after chronic leptin administration, rats from each of the treatment groups described above underwent an intravenous tolbutamide tolerance test on treatment day 14 or 15. The AUCs for insulin, calculated from 0 to $60 \mathrm{~min}$ (intravenous tolbutamide administration at 0 min), are shown in Fig. $2 C$. The insulin secretory response to the intravenous tolbutamide challenge was similar across the four treatments groups. Again, there was a tendency for the insulin AUC to be lower in the HF-Lep group and in the case of tolbutamide treatment was also slightly reduced in the HF-FR group.

Experimental protocol 2. The glucose infusion rates necessary to maintain euglycemia $(111 \pm 2 \mathrm{mg} / \mathrm{dl}$ for HF-FR, $115 \pm 2 \mathrm{mg} / \mathrm{dl}$ for HF-Lep) during hyperinsulinemia are shown in Fig. 3. There was a significant increase in the glucose infusion rate for the HF-Lep rats compared with HF-FR rats, indicating that chronic leptin treatment of glucose-intolerant rats resulted in an increase in the insulin-mediated glucose clearance rate.

Experimental protocol 3. At day 0 of the experimental treatment period, body mass of the HF-Lep, HF, and HF-FR groups were similar, but all high-fat diet animals were significantly heavier than the Con animals (Table 3). After the 12-day treatment period, body mass of the HF-Lep and HF-FR animals was reduced compared with day 0 . However, at day 12, the body mass of the HF-Lep, HF, and HF-FR animals remained greater than that of the Con group.

Sol mass was similar among the high-fat diet groups and among the Con, HF, and HF-FR groups (Table 3), although the mass of the Sol in the HF-Lep animals was heavier compared with Con animals. Plant mass was similar between the HF-Lep and HF animals, but Plant muscles of both groups were significantly heavier compared with Con animals (Table 3). HF animals were also found to have Plant muscles that were heavier than the HF-FR animals. Epididymal fat pad mass was similar among the HF-Lep, HF, and HF-FR groups (Table 3). Con animals had significantly lighter epididymal fat pads compared with the HF-Lep, HF, and HF-FR groups.

The rates of submaximal insulin-stimulated skeletal muscle glucose uptake were reduced by $\sim 48$ and $25 \%$ in the HF and HF-FR animals, respectively, when compared with the Con group (Fig. 4). In contrast, rates of insulin-stimulated glucose uptake were not different between the Con and HF-Lep animals. Glucose uptake in the hindlimbs of the HF-Lep animals was greater than that of the HF-FR animals, and HF-FR animals had rates of glucose uptake that were greater than the $\mathrm{HF}$ animals.

Rates of glucose transport were determined in the Sol, Plant, WG, and RG under submaximal insulinstimulated conditions using the glucose analog 3-MG (Fig. 5). 3-MG is carried by the glucose transporter but is not phosphorylated, which results in its intracellular accumulation representing the glucose transport process independent of intracellular disposal. The rates of 3-MG transport in the Sol, Plant, and RG were significantly reduced in the HF animals compared with both the Con and HF-Lep animals. Similarly, rates of 3-MG transport in the Sol, Plant, and RG of the HF-FR group were reduced compared with Con and HF-Lep animals. However, no difference in rates of 3-MG transport in the Sol, Plant, and RG existed between the HF and HF-FR groups. Rates of 3-MG transport in the WG were similar among all experimental groups.

Total GLUT-4 protein concentrations in the Sol, Plant, and RG (Fig. 6) and quadricep (Fig. 7) were significantly greater in the Con and HF-Lep animals compared with either the HF or HF-FR groups. No difference in GLUT-4 protein concentration existed in the Sol, Plant, and RG between Con and HF-Lep or HF and HF-FR animals (Fig. 6). GLUT-4 protein concen- 
Fig. 3. Glucose infusion rates during hyperinsulinemic $\left(4 \mathrm{mU} \cdot \mathrm{kg}^{-1} \cdot \mathrm{min}^{-1}\right.$ begun at time 0 )-euglycemic clamp of HF-FR $(n=6)$ or HF-Lep $(n=5)$ rats. Values are means \pm SE. There was a significant effect of time $(F=89.560$, $P<0.0001)$ and a significant interaction of time and treatment $(F=1.808$, $P<0.05$ ), whereas the main effect for treatment approached significance $(F=3.885, P=0.08)$.

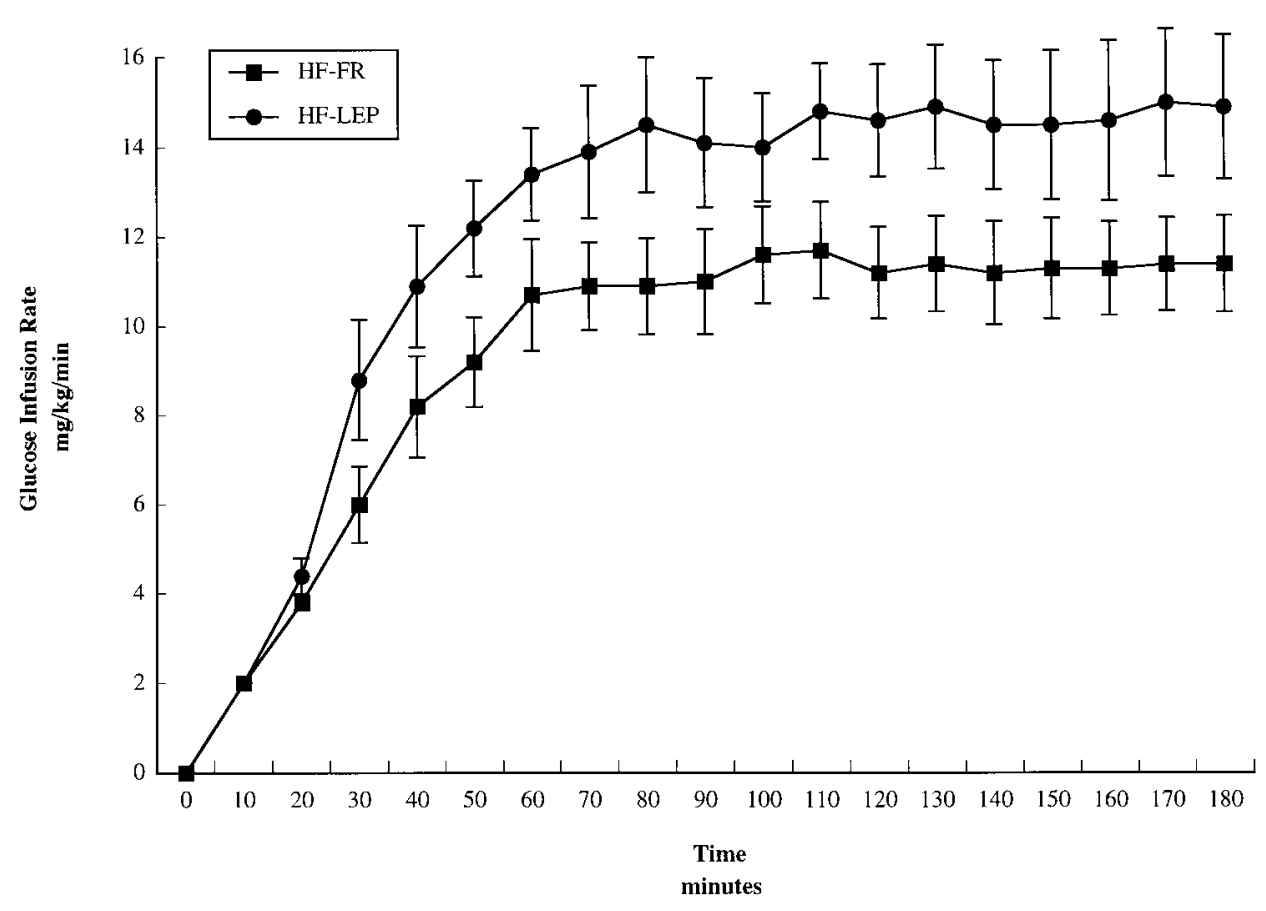

tration in the WG was similar among all experimental groups (Fig. 6).

Insulin-stimulated plasma membrane GLUT-4 protein concentration was similar in the Con and HF-Lep animals and was significantly greater compared with the HF group (Fig. 7). Protein concentration (mg/g wet wt) of the plasma membrane fractions was similar across the three treatment groups (Con: $0.57 \pm 0.03$; HF-Lep: $0.56 \pm 0.09$; HF: $0.55 \pm 0.05$ ). Assessment of $5^{\prime}$-nucleotidase activity $\left(\mu \mathrm{mol} \cdot \mathrm{min}^{-1} \cdot \mathrm{mg}\right.$ protein $\left.^{-1}\right)$ indicated that the plasma membrane fractions were purified compared with the crude homogenate (Con: $52.6 \pm 1.4$ vs. $147.2 \pm 9.8$; HF-Lep: $42.0 \pm 3.9$ vs. $172.9 \pm 6.6$; HF: $37.4 \pm 1.4$ vs. $167.7 \pm 9.1$ ).

After the 12-day treatment period, muscle glycogen concentration was similar in the Plant, RG, and WG among all experimental animals in perfusion group 1 (Table 4). In contrast, glycogen concentration in the Sol of the Con group was significantly greater compared with HF-Lep, HF, and HF-FR animals. The glycogen concentration in the Sol of the HF-FR animals was also greater compared with the HF-Lep animals. Intramuscular triglyceride (IMTG) content was assessed in the quadriceps of animals in perfusion group 2 (Table 4 ). A 3-mo high-fat diet significantly increased intramuscular triglyceride content as evidenced in the HF group compared with Con. Of interest, a 12-day leptin treatment period significantly reduced intramuscular triglyceride levels such that the intramuscular triglyceride of the Con and HF-Lep animals was similar.

Skeletal muscle enzyme activity data are shown in Table 5. Hexokinase activity was similar among all experimental groups and muscles except in the Sol. Hexokinase activity in the Sol of the Con group was significantly greater compared with $\mathrm{HF}$ and HF-FR animals. Citrate synthase activity was similar across all experimental groups and skeletal muscles assessed (Table 5). $\beta$-OAC activity was similar in the Sol and RG of all experimental groups (Table 5). However, $\beta$-OAC activity was significantly elevated in the Plant and WG of the HF-Lep, HF, and HF-FR groups compared with Con animals.

Chronic leptin administration has been reported to increase whole body glucose clearance, insulin-stimulated skeletal muscle glucose uptake, and 3-MG trans-

\section{DISCUSSION}

Table 3. Body, muscle, and epididymal fat pad mass of animals in hindlimb perfusion group 1

\begin{tabular}{|c|c|c|c|c|}
\hline & Con $(n=7)$ & HF-Lep $(n=7)$ & $\mathrm{HF}(n=7)$ & HF-FR $(n=7)$ \\
\hline \multicolumn{5}{|l|}{ Body mass, $\mathrm{g}$} \\
\hline Treatment day 0 & $605 \pm 21$ & $764 \pm 30^{*}$ & $761 \pm 28^{*}$ & $764 \pm 32^{*}$ \\
\hline Treatment day 12 & $613 \pm 22$ & $740 \pm 32 * \div$ & $762 \pm 34^{*}$ & $747 \pm 25^{*} \ddagger$ \\
\hline \multicolumn{5}{|l|}{ Muscle mass, mg } \\
\hline Soleus & $222.3 \pm 10.3$ & $276.1 \pm 14.1^{*}$ & $254.5 \pm 9.5$ & $247.1 \pm 15.9$ \\
\hline Plantaris & $514.1 \pm 16.0$ & $583.0 \pm 16.4^{*}$ & $591.0 \pm 23.5^{*}$ & $532.0 \pm 19.5 \dagger$ \\
\hline Epididymal fat pad mass, $\mathrm{g}$ & $14.1 \pm 1.3$ & $22.7 \pm 2.1^{*}$ & $26.4 \pm 2.9^{*}$ & $24.4 \pm 1.4^{*}$ \\
\hline
\end{tabular}

Values are means $\pm \mathrm{SE} ; n$, no. of animals. *Significantly different from Con $(P<0.05)$. $†$ Significantly different from HF $(P<0.05)$. $\ddagger$ Significantly different from day $0(P<0.05)$. 


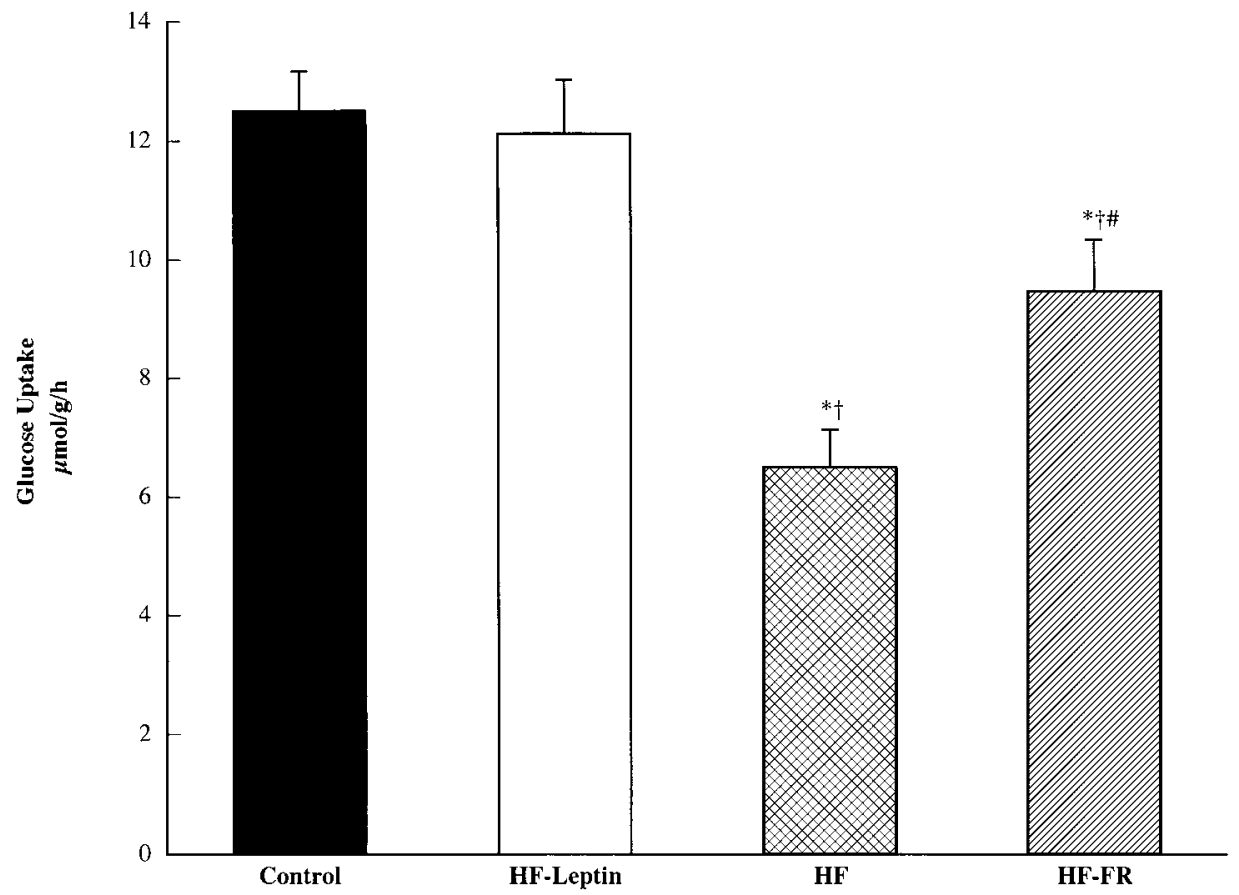

Fig. 4. Glucose uptake in hindlimbs of Con, HF-Lep, HF, and HF-FR rats during perfusion with $8 \mathrm{mM}$ glucose and a submaximal $(500 \mu \mathrm{U} / \mathrm{ml})$ insulin concentration; $n=7 /$ group. Values are means \pm SE. *Significantly different from Con $(P<0.05)$. $†$ Significantly different from HF-Lep $(P<0.05)$. \# Significantly different from $\mathrm{HF}(P<0.05)$. port in non-insulin-resistant rats $(3,44,60)$. However, little information has been presented to date that has evaluated the effect of chronic leptin administration in glucose-intolerant rodents. In this investigation, we provided male Wistar rats a high-fat diet before leptin treatment as this feeding regimen has previously been shown to induce skeletal muscle insulin resistance in rats $(48,49)$. This diet was effective in inducing an insulin-resistant state as it was observed that glucose tolerance was significantly impaired in high-fat-fed animals (Fig. 1).

Our initial inquiry was to determine if chronic leptin administration improved whole body glucose tolerance in the high-fat-diet-induced insulin-resistant rats (Fig. 2). To assess these effects, we subjected animals to an intravenous glucose tolerance test. Glucose AUC in the HF-Lep animals were similar to those of the Con animals and were significantly reduced compared with the
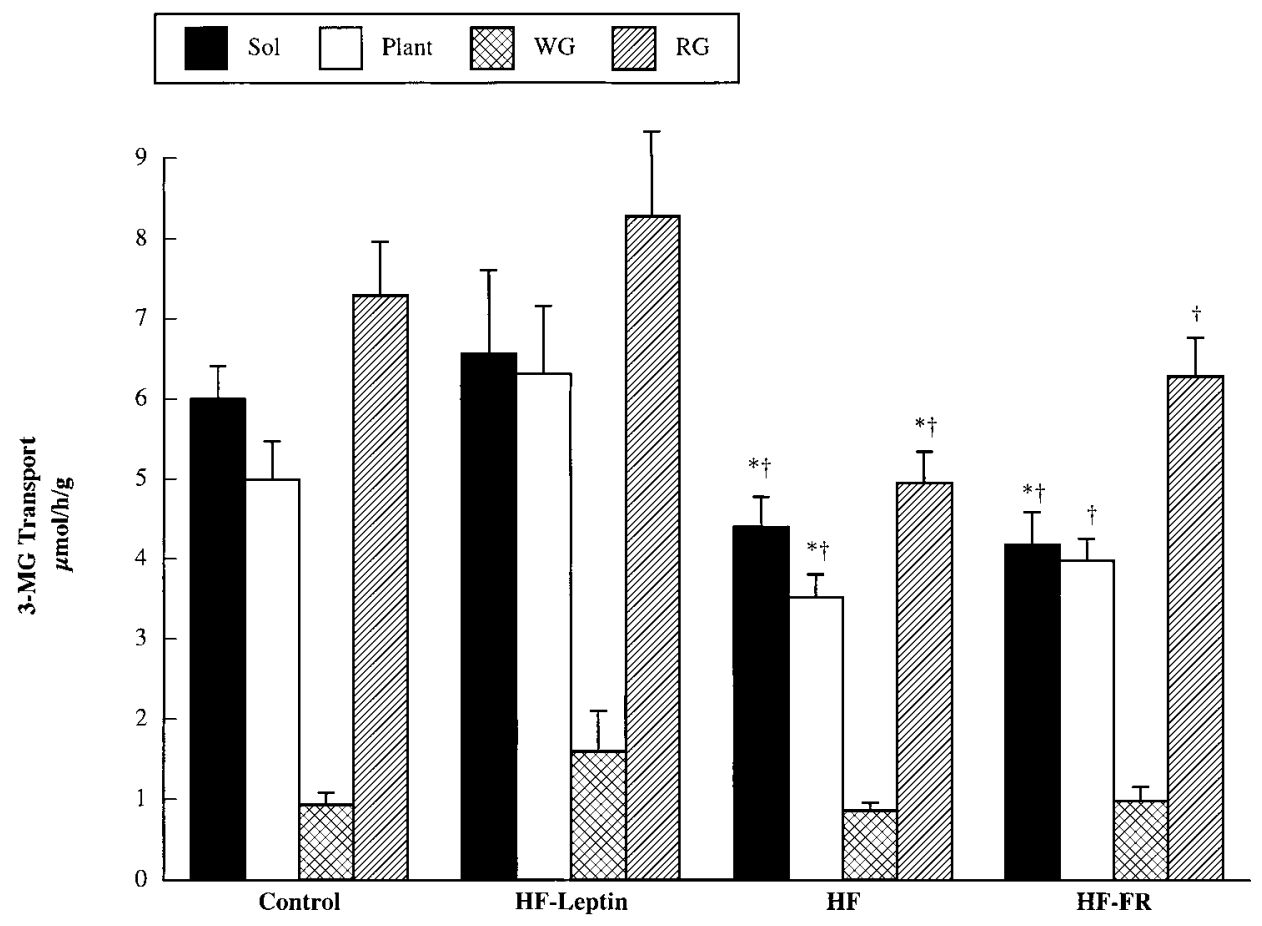

Fig. 5. 3-O-methylglucose (3-MG) transport in the presence of $500 \mu \mathrm{U} / \mathrm{ml}$ insulin in hindlimb muscles of Con, HF-Lep, HF, and HF-FR rats; $n=7$ /group. Sol, soleus; Plant, plantaris; WG, white gastrocnemius; RG, red gastrocnemius. Values are means \pm SE. * Significantly different from Con $(P<0.05)$. $†$ Significantly different from HF-Lep $(P<$ 0.05 ). 
Fig. 6. GLUT-4 protein concentration, expressed as a percentage of a heart standard, in skeletal muscles from rats that were divided among 1 of 4 groups: Con, HF-Lep, HF, and HF-FR; $n=$ 7/group. Values are means $\pm \mathrm{SE}$. * Significantly different from Con $(P<$ $0.05)$. $†$ Significantly different from $\mathrm{HF}$ Lep $(P<0.05)$.

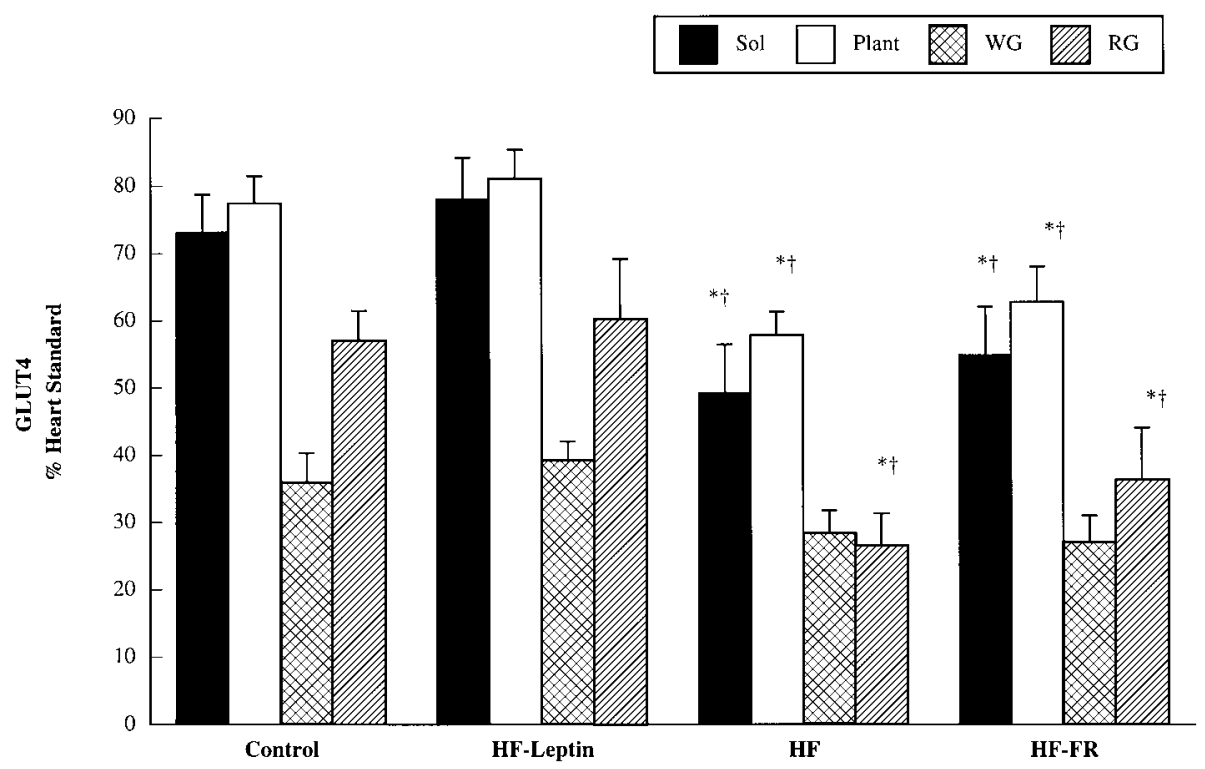

HF animals. Of particular interest, the decreased glucose AUC in the HF-Lep animals occurred with insulin AUC being slightly lowered. It has been reported that chronic leptin administration inhibits insulin secretion from isolated islets (35) and perfused rat pancreas (18). To further characterize the effects of chronic leptin administration on pancreatic function, we subjected animals to an intravenous tolbutamide tolerance test. Tolbutamide binds to the sulfonylurea receptor in the $\beta$-cells of the pancreas, which blocks the $\mathrm{K}_{\mathrm{ATP}}$ channels, leading to an increased intracellular $\mathrm{Ca}^{2+}$ concentration and increased insulin secretion (32). Unlike the isolated islet or perfused pancreas studies, we did not find a difference in tolbutamide-stimulated insulin secretion across treatment groups. These observations suggest that improvements in whole body glucose tolerance after chronic leptin treatment result from changes in insulin action, as opposed to alterations in pancreatic insulin secretion. This contention is further supported by our observation that insulin-mediated glucose clearance was enhanced in leptin-treated animals during a hyperinsulinemic-euglycemic clamp (Fig. 3). Although these observations have not been reported previously in insulin-resistant animals, they are consistent with those investigations that have administered leptin to non-insulin-resistant animals and subsequently found improvements in whole body insulin sensitivity and glucose clearance rates $(2,3,43)$.

As over $80 \%$ of a glucose load is disposed of by skeletal muscle (14), it was determined if alterations in skeletal muscle might account for the suppressed whole body glucose disposal rates in response to a high-fat diet. Rates of insulin-stimulated skeletal muscle glucose uptake (Fig. 4) and 3-MG transport (Fig. 5) were reduced significantly in the HF and HF-FR animals. This observation is consistent with Wilkes et al. (58), Hansen et al. (22), and Buettner et al. (8) who reported that a high-fat diet reduces insulin-stimu-
Fig. 7. Total and insulin-stimulated plasma membrane (PM) GLUT-4 protein concentration, expressed as a percentage of a heart standard, in quadricep muscles from rats that were divided among 1 of 3 groups (Con, HF-Lep, and $\mathrm{HF}$ ) and subjected to hindlimb perfusion; $n=8$ /group. Values are means \pm SE. * Significantly different from Con $(P<0.05)$. † Significantly different from HF-Lep $(P<0.05)$.

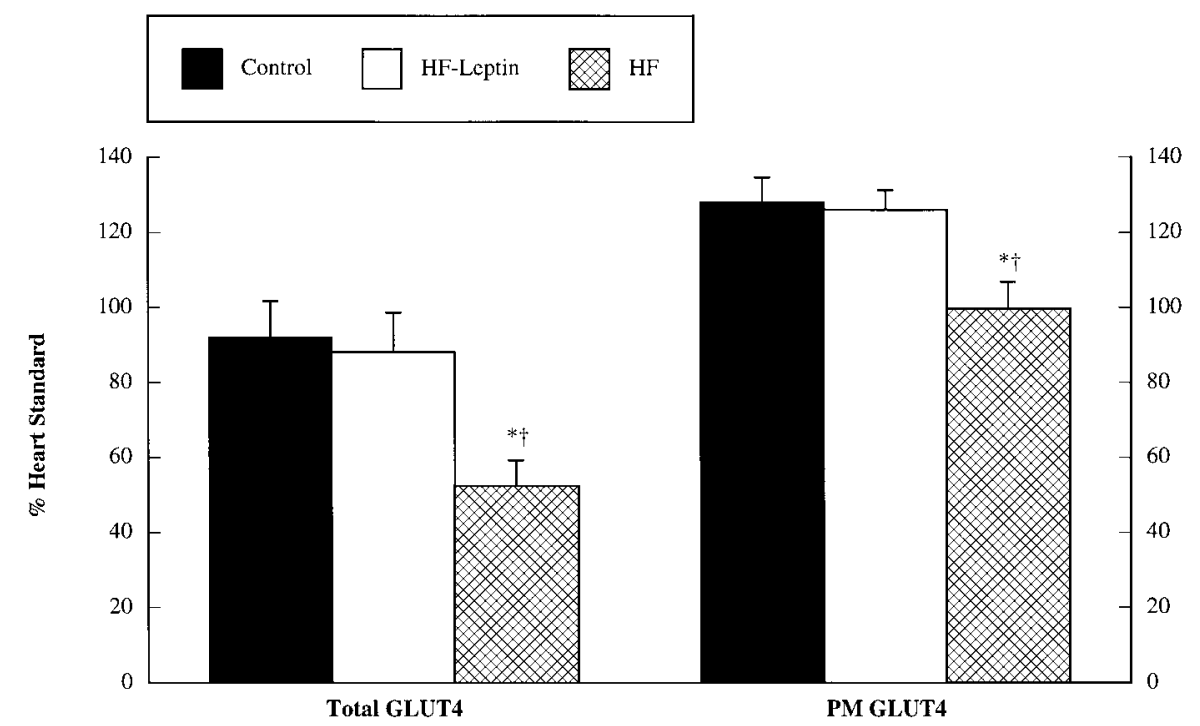


Table 4. Glycogen and intramuscular triglyceride concentration in selected muscles from male Wistar rats after the 12-day treatment period

\begin{tabular}{|c|c|c|c|c|}
\hline & Con & HF-Lep & $\mathrm{HF}$ & HF-FR \\
\hline \multicolumn{5}{|c|}{ Glycogen (glucosyl units), $\mu \mathrm{mol} / \mathrm{g}$ wet wt } \\
\hline$n$ & 7 & 7 & 7 & 7 \\
\hline Soleus & $38.83 \pm 1.1$ & $27.47 \pm 2.1^{*}$ & $27.88 \pm 2.0^{*}$ & $33.11 \pm 2.0 * \dagger$ \\
\hline Plantaris & $44.81 \pm 3.7$ & $34.23 \pm 4.1$ & $36.60 \pm 4.0$ & $35.65 \pm 3.4$ \\
\hline WG & $50.83 \pm 2.9$ & $44.75 \pm 4.0$ & $46.52 \pm 1.9$ & $41.63 \pm 3.6$ \\
\hline $\mathrm{RG}$ & $42.04 \pm 2.7$ & $40.84 \pm 3.8$ & $39.00 \pm 3.6$ & $45.95 \pm 1.3$ \\
\hline \multicolumn{5}{|c|}{ Intramuscular triglycerides, $\mathrm{mg} / \mathrm{g}$ wet wt } \\
\hline$n$ & 8 & 8 & 8 & ND \\
\hline Quadricep & $1.99 \pm 0.19$ & $4.07 \pm 1.19$ & $6.49 \pm 0.50 * \dagger$ & \\
\hline
\end{tabular}

Values are means $\pm \mathrm{SE} ; n$, no. of animals. WG, white gastrocnemius; RG, red gastrocnemius. ND, not determined as perfusion group 2 did not have a HF-FR group (see METHODS). * Significantly different from Con $(P<0.05)$. $†$ Significantly different from HF-Lep $(P<0.05)$.

lated 3-MG transport $(22,58)$ and 2-deoxyglucose uptake $(8,22)$ in rodent skeletal muscle. The key observation in the present investigation was that 12 days of leptin administration completely reversed high-fat-diet-induced skeletal muscle insulin resistance, resulting in similar rates of insulin-stimulated skeletal muscle glucose uptake and 3-MG transport in Con and HF-Lep animals.

The high-fat diet appeared to induce skeletal muscle insulin resistance by suppressing the expression of the glucose transporter GLUT-4 (Fig. 6). This observation is similar to that of Kahn and Pedersen (26), who reported total GLUT-4 protein concentration is reduced in quadricep muscle of Sprague-Dawley rats subjected to a high-fat diet. Hansen et al. (22) also investigated the effects of a high-fat diet on GLUT-4 protein in rodent skeletal muscle. Although these investigators, did not evaluate total skeletal muscle GLUT-4 protein concentration, they did find that a high-fat diet reduced insulin-stimulated cell surface GLUT-4 protein concentration. In agreement with Hansen et al., we observed insulin-stimulated translocation of glucose transporters to the plasma membrane to be reduced in the HF animals (Fig. 7).

Most striking, we found that 12 days of leptin administration completely normalized total skeletal mus- cle (Figs. 6 and 7) and insulin-stimulated plasma membrane GLUT-4 protein concentrations (Fig. 7) in animals fed a high-fat diet. When rates of 3-MG transport (Fig. 5) and skeletal muscle GLUT-4 protein concentration (Fig. 6) were compared, the alterations in total skeletal muscle GLUT-4 protein concentration could virtually account for either the reduction or elevation in rates of insulin-stimulated 3-MG transport. This observation is consistent with previous reports that have shown insulin-stimulated skeletal muscle 3-MG glucose transport rates to be related to the total GLUT-4 protein concentration (1, 7, 23, 28). Furthermore, several investigations have demonstrated that the total pool of skeletal muscle GLUT-4 protein is associated with the amount of GLUT- 4 translocated to the plasma membrane in response to insulin $(15,40)$. Therefore, it is reasonable to suggest that insulinstimulated skeletal muscle 3-MG transport was improved in the HF-Lep animals due to leptin treatment normalizing the total GLUT-4 protein concentration, which in turn resulted in a greater number of glucose transporters being translocated to the plasma membrane in response to insulin. However, chronic leptin administration did not appear to affect 3-MG transport or GLUT-4 protein concentration in the WG (a type IIb

Table 5. Enzymatic activities in selected muscles from male Wistar rats after the 12-day treatment period

\begin{tabular}{|c|c|c|c|c|}
\hline & $\operatorname{Con}(n=7)$ & $\begin{array}{l}\text { HF-Lep } \\
(n=7)\end{array}$ & $\mathrm{HF}(n=7)$ & $\begin{array}{l}\text { HF-FR } \\
(n=7)\end{array}$ \\
\hline \multicolumn{5}{|c|}{ Hexokinase activity, $\mu \mathrm{mol} \cdot \mathrm{g}^{-1} \cdot \min ^{-1}$} \\
\hline Soleus & $3.01 \pm 0.1$ & $2.74 \pm 0.2$ & $2.50 \pm 0.1^{*}$ & $2.63 \pm 0.1^{*}$ \\
\hline Plantaris & $2.10 \pm 0.1$ & $2.13 \pm 0.1$ & $2.22 \pm 0.1$ & $2.06 \pm 0.2$ \\
\hline WG & $1.04 \pm 0.06$ & $0.96 \pm 0.06$ & $0.98 \pm 0.04$ & $0.93 \pm 0.05$ \\
\hline RG & $2.10 \pm 0.1$ & $1.96 \pm 0.1$ & $1.82 \pm 0.1$ & $1.95 \pm 0.1$ \\
\hline \multicolumn{5}{|c|}{ Citrate synthase activity, $\mu \mathrm{mol} \cdot \mathrm{g}^{-1} \cdot \min ^{-1}$} \\
\hline Soleus & $47.47 \pm 2.0$ & $47.19 \pm 1.4$ & $46.94 \pm 2.3$ & $45.24 \pm 3.1$ \\
\hline Plantaris & $50.65 \pm 2.1$ & $52.79 \pm 1.8$ & $50.08 \pm 1.3$ & $54.65 \pm 2.3$ \\
\hline WG & $23.26 \pm 2.3$ & $27.34 \pm 2.9$ & $26.71 \pm 1.7$ & $25.63 \pm 2.8$ \\
\hline $\mathrm{RG}$ & $56.46 \pm 2.6$ & $58.30 \pm 3.0$ & $57.62 \pm 2.2$ & $56.97 \pm 2.0$ \\
\hline \multicolumn{5}{|c|}{$\beta$-OAC activity, $\mu \mathrm{mol} \cdot \mathrm{g}^{-1} \cdot \min ^{-1}$} \\
\hline Soleus & $58.67 \pm 1.4$ & $59.49 \pm 1.6$ & $63.97 \pm 2.3$ & $61.65 \pm 2.8$ \\
\hline Plantaris & $27.32 \pm 2.0$ & $37.69 \pm 2.1^{*}$ & $35.30 \pm 2.4^{*}$ & $37.41 \pm 2.8 *$ \\
\hline WG & $8.06 \pm 0.4$ & $9.91 \pm 0.7 *$ & $9.84 \pm 0.6^{*}$ & $10.37 \pm 0.7^{*}$ \\
\hline $\mathrm{RG}$ & $31.01 \pm 2.0$ & $33.82 \pm 2.0$ & $34.37 \pm 2.4$ & $36.52 \pm 3.1$ \\
\hline
\end{tabular}

Values are means $\pm \mathrm{SE} ; n$, no. of animals. $\beta$-OAC, $\beta$-hydroxyacetyl-CoA dehydrogenase. * Significantly different from Con $(P<0.05)$. 
fiber), which suggests that leptin does not affect the glucose transport pathway in glycolytic muscle fibers.

While plausible to suggest that chronic leptin administration improves insulin-stimulated glucose uptake and transport due to reductions in visceral fat concentration, it has been reported recently that the effect of leptin administration on peripheral insulin action cannot be explained solely by decreases in visceral fat deposition (2). Therefore, the possibility exists that secondary effects in response to leptin treatment may have accounted for these effects. Leptin administration alters skeletal muscle metabolism by shifting the muscle from lipid storage to fat oxidation (33). Because a reduction in skeletal muscle triglyceride levels improves whole body glucose tolerance (30), leptin may improve insulin-stimulated glucose uptake and transport, in part, by altering the intramuscular triglyceride concentration (8). This possibility is consistent with our finding that leptin administration for 12 days reduced intramuscular triglyceride levels in animals that had been subjected to 3 mo of a high-fat diet (Table 4). Chronic leptin treatment may also improve an insulinresistant state by attenuating the effects of an elevated blood tumor necrosis factor- $\alpha$ (TNF- $\alpha$ ) level. TNF- $\alpha$ is secreted from highly active adipocytes in the abdominal region, and serum TNF- $\alpha$ levels have been reported to be elevated in obese, type II diabetics (27). An excess of TNF- $\alpha$ attenuates in vitro expression of GLUT-4 (46), inhibits insulin receptor tyrosine kinase activity (24), and impairs insulin-stimulated glucose uptake in $\mathrm{C}_{2} \mathrm{C}_{12}$ muscle cells (16). Of particular relevance, exogenous leptin administration has been reported to attenuate the effects of elevated TNF- $\alpha$ levels (50).

Alternatively, the improvements in insulin-stimulated glucose uptake and transport may be due to leptin exerting a primary effect in the skeletal muscle. Skeletal muscle expresses both long and short isoforms of the leptin receptor $(20,51)$. The leptin receptor is a member of the gp130 family of cytokine receptors, which stimulate gene transcription via activation of cytosolic STAT proteins (5). Both leptin receptor isoforms have signal transduction capabilities $(20,34)$. Although the activation and effect of these signals in skeletal muscle in response to chronic leptin administration are unknown, it is possible that chronic leptin treatment may improve insulin-stimulated glucose transport in skeletal muscle by initiating increases in GLUT-4 protein concentration.

Rates of skeletal muscle glucose uptake and transport can be elevated in response to increased whole body energy expenditure $(21,37)$ and/or decreased caloric intake $(11,60)$, both of which could result in a reduced muscle glycogen concentration. A reduction in muscle glycogen will facilitate insulin-stimulated glucose uptake and transport (19). However, muscle glycogen concentration was similar across all treatment groups, with the exception of the Sol (Table 4). Therefore, muscle glycogen levels cannot completely account for differences in rates of glucose uptake and transport that were observed among the experimental groups (Figs. 4 and 5). This finding is in agreement with Dean et al. (13) who reported that caloric restriction does not reduce skeletal muscle glycogen levels or directly influence rates of insulin-stimulated glucose transport. Cartee and associates $(10,13)$ have reported that caloric intake can influence insulin action and membrane permeability to glucose in skeletal muscle. Although 3-MG transport may have been elevated in the HF-Lep animals due to caloric restriction, the HF-Lep and HF-FR animals consumed a similar amount of food throughout the experimental period. Thus any differences in insulin-stimulated glucose uptake and transport that existed between the HF-Lep and HF-FR animals can presumably be attributed to the effects of chronic leptin treatment.

In summary, we found that a high-fat diet reduced glucose tolerance and insulin-stimulated skeletal muscle glucose disposal, glucose uptake, and 3-MG transport. Insulin resistance in the skeletal muscles of the animals subjected to the high-fat diet appeared to be due to a reduced GLUT-4 protein concentration. Animals subjected to a high-fat diet and subsequently treated with leptin exhibited rates of insulin-stimulated glucose uptake and 3-MG transport that were identical to Con animals. It appeared that this improvement was due to leptin treatment reversing a high-fat diet-induced skeletal muscle insulin resistance, at least in part, by normalizing the total skeletal muscle GLUT-4 protein concentration.

We thank Lily Ansari and Ric O'Conner for excellent technical assistance.

Work done at California State University Northridge was supported in part by National Institute of General Medical Sciences Grant GM-48680, the California State University-Northridge Probationary Faculty Support Program, and by Amgen, Inc.

Current address for N. Levin: Trega Biosciences Inc., 9880 Campus Point Dr., San Diego, CA 92121 (E-mail: nlevin@trega.com).

\section{REFERENCES}

1. Banks EA, Brozinick, Jr JT, Yaspelkis BB III, Kang HY, and Ivy JL. Muscle glucose transport, GLUT4 content and degree of exercise training in obese Zucker rats. Am J Physiol Endocrinol Metab 263: E1010-E1015, 1992.

2. Barzilai N, She L, Liu L, Wang J, Hu M, Vuguin P, and Rossetti L. Decreased visceral adiposity accounts for leptin effect on hepatic but not peripheral insulin action. Am J Physiol Endocrinol Metab 277: E291-E298, 1999.

3. Barzilai N, Wang J, Massilon D, Vuguin P, Hawkins M, and Rossetti L. Leptin selectively decreases visceral adiposity and enhances insulin action. J Clin Invest 100: 3105-3110, 1997.

4. Bass A, Brdiczka D, Eyer P, Hofer S, and Pette D. Metabolic differentiation of distinct muscle types at the level of enzymatic organization. Eur J Biochem 10: 198-206, 1969.

5. Baumann H, Morella KK, White DW, Dembski M, Bailon PS, Kim H, Lai CF, and Tartaglia LA. The full-length leptin receptor has signaling capabilities of interleukin 6-type receptors. Proc Natl Acad Sci USA 93: 8374-8378, 1996.

6. Bradford MM. A rapid and sensitive method for the quantitation of microgram quantities of protein utilizing the principle of protein-dye binding. Anal Biochem 72: 248-254, 1976.

7. Brozinick Jr JT, Etgen, Jr GJ, Yaspelkis BB III, Kang HY, and Ivy JL. Effects of exercise training on muscle GLUT4 protein content and translocation in obese Zucker rats. Am J Physiol Endocrinol Metab 265: E419-E427, 1993.

8. Buettner R, Newgard CB, Rhodes CJ, and O'Doherty RM. Correction of diet-induced hyperglycemia, hyperinsulinemia, 
and skeletal muscle insulin resistance by moderate hyperleptinemia. Am J Physiol Endocrinol Metab 278: E563-E569, 2000.

9. Burton GW, Webb A, and Ingold KU. Methods: a mild, rapid and effecient method of lipd extraction for use in determining vitamin E/lipid ratios. Lipids 20: 29-39, 1985.

10. Cartee G, Kietzke E, and Briggs-Tung C. Adaptation of muscle glucose transport with caloric restriction in adult, middle-aged, and old rats. Am J Physiol Regulatory Integrative Comp Physiol 266: R1443-R1447, 1994.

11. Chen G, Koyama K, Yuan X, Lee Y, Zhou Y-T, O'Doherty R, Newgard CB, and Unger RH. Disappearance of body fat in normal rats induced by adenovirus-mediated leptin gene therapy. Proc Natl Acad Sci USA 93: 14795-14799, 1996.

12. Cioffi JA, Shafer AW, Zupancic TJ, Smith-Gbur J, Mikhail A, Platika D, and Snodgrass HR. Novel B219/OB receptor isoforms: possible role of leptin in hematopoiesis and reproduction. Nat Med 2: 585-589, 1996.

13. Dean JJ, Brozinick, Jr JT, Cushman SW, and Cartee GD. Calorie restriction increases cell surface GLUT-4 in insulinstimulated skeletal muscle. Am J Physiol Endocrinol Metab 275: E957-E964, 1998

14. Defronzo RA, Jacot E, Jequier E, Maeder E, Wahren J, and Felber JP. The effect of insulin on the disposal of intravenous glucose. Results from indirect calorimetry and hepatic and femoral venous catheterization. Diabetes 30: 1000-1007, 1981.

15. Dela F, Mikines KJ, Linstow M, Seccher NH, and Galbo H. Effect of training on insulin-mediated glucose uptake in human muscle. Am J Physiol Endocrinol Metab 263: E1134-E1143, 1992.

16. Del Aguila LF, Claffey KP, and Kirwan JP. TNF- $\alpha$ impairs insulin signaling and insulin stimulation of glucose uptake in $\mathrm{C}_{2} \mathrm{C}_{12}$ muscle cells. Am J Physiol Endocrinol Metab 276: E849E855, 1999

17. Després JP. Abdominal obesity as an important component of insulin resistance syndrome. Nutrition 9: 452-459, 1993.

18. Fehmann HC, Peiser C, Bode HP, SM, Staats P, Hedetoft C, Lang RE, and Goke B. Leptin: a potent inhibitor of insulin secretion. Peptides 18: 1267-1273, 1997.

19. Fell RD, Terblanche SE, Ivy JL, Young JC, and Holloszy JO. Effect of muscle glycogen content on glucose uptake following exercise. J Appl Physiol 52: 434-437, 1982.

20. Ghilardi N, Ziegler S, Wiestner A, Stoffel R, Heim M, and Radek SC. Defective STAT signaling by the leptin receptor in diabetic mice. Proc Natl Acad Sci USA 93: 6231-6235, 1996.

21. Halaas JL, Gajiwala KS, Maffei M, Cohen SL, Chait BT, Rabinowitz D, Lallone RL, Burley SK, and Friedman JF. Weight-reducing effects of the plasma protein encoded by the obese gene. Science 269: 543-546, 1995.

22. Hansen PA, Han DH, Marshall BA, Nolte LA, Chen MM, Mueckler M, and Holloszy JO. A high fat diet impairs stimulation of glucose transport in muscle. Functional evaluation of potential mechanisms. J Biol Chem 273: 26157-26163, 1998.

23. Henriksen EJ, Bourey RE, Rodnick KJ, Koranyi L, Permutt MA, and Holloszy JO. Glucose transporter protein content and glucose transport capacity in rat skeletal muscles. Am $J$ Physiol Endocrinol Metab 259: E593-E598, 1990.

24. Hotamisligil GS and Spiegelman BM. Tumor necrosis factor $\alpha$ : a key component of the obesity-diabetes link. Diabetes 43: 1271-1278, 1994.

25. Ivy JL, Brozinick, Jr. JT, Torgan CE, and Kastello GM. Skeletal muscle glucose transport in obese Zucker rats after exercise training. J Appl Physiol 66: 2635-2641, 1989.

26. Kahn BB and Pedersen O. Suppression of GLUT4 expression in skeletal muscle of rats that are obese from high fat feeding but not from high carbohydrate feeding or genetic obesity. Endocrinology 132: 13-22, 1993.

27. Katsuki A, Sumida Y, Murashima S, Murata K, Takarada Y, Ito K, Fujii M, Tsuchihashi K, Goto H, Nakatani K, and Yano Y. Serum levels of tumor necrosis factor-alpha are increased in obese patients with non-insulin dependent diabetes mellitus. J Clin Endocrinol Metab 83: 859-862, 1998.

28. Kern M, Wells JA, Stevens JM, Elton CW, Friedman JE, Tapscott EB, Pekala PH, and Dohm GL. Insulin responsive- ness in skeletal muscle is determined by glucose transporter (GLUT4) protein level. Biochem J 270: 397-400, 1990.

29. Kieffer TJ, Heller RS, and Habner JF. Leptin receptors expressed on pancreatic beta-cells. Biochem Biophys Res Commun 224: 522-527, 1996.

30. Koyama K, Chen G, Lee Y, and Unger RH. Tissue triglycerides, insulin resistance, and insulin production: implications for hyperinsulinemia of obesity. Am J Physiol Endocrinol Metab 273: E708-E713, 1997.

31. Laemmli UK. Cleavage of structural proteins during the assembly of the head of bacteriophase T4. Nature 227: 680-685, 1970.

32. Mariot $\mathbf{P}$, Gilon $\mathbf{P}$, Nenquin $\mathbf{M}$, and Henquin JC. Tolbutamide and diazoxide influence insulin secretion by changing the concentration but not the action of cytoplasmic $\mathrm{Ca}^{2+}$ in $\beta$-cells. Diabetes 47: 365-373, 1998.

33. Muoio DM, Dohm GL, Fiedorek FT, Tapscott EB, and Coleman RA. Leptin directly alters lipid partitioning in skeletal muscle. Diabetes 46: 1360-1363, 1997.

34. Murakami T, Yamashita T, Iida M, Kuwajima M, and Shima K. A short form of leptin receptor performs signal transduction. Biochem Biophys Res Commun 231: 26-29, 1997.

35. Pallett AL, Morton NM, Cawthorne MA, and Emilsson V. Leptin inhibits insulin secretion and reduces insulin mRNA levels in rat isolated pancreatic islets. Biochem Biophys Res Commun 238: 267-270, 1997.

36. Passonneau JV and Lauderdale VR. A comparison of three methods of glycogen measurement in tissues. Anal Biochem 60: 405-412, 1974.

37. Pellymounter MA, Cullen MJ, Baker MB, Hecht R, Winters D, Boone T, and Collins F. Effects of the obese gene product on body weight regulation in ob/ob mice. Science 269: 540-543, 1995.

38. Poitout V, Rouault C, Guerre-Millo M, and Reach G. Does leptin regulate insulin secretion? Diabetes Metab 24: 321-326, 1998

39. Reaven GM. Pathophysiology of insulin resistance in human disease. Physiol Rev 76: 473-486, 1995.

40. Reynolds TH, Brozinick JT, Rogers MA, and Cushman SW. Effects of exercise training on glucose transport and cellsurface GLUT-4 in isolated rat epitrochlearis muscle. Am $J$ Physiol Endocrinol Metab 274: E773-E778, 1997.

41. Ruderman NB, Houghton CRS, and Helms R. Evaluation of the isolated perfused rat hindquarter for the study of muscle metabolism. Biochem J 124: 639-651, 1971.

42. Sherman WM, Katz AL, Cutler CL, Withers RT, and Ivy JL. Glucose transport: locus of muscle insulin resistance in obese Zucker rats. Am J Physiol Endocrinol Metab 255: E374-E382, 1988.

43. Shi ZQ, Nelson A, Whitcomb L, Wang J, and Cohen AM. Intracerebroventricular administration of leptin markedly enhances insulin sensitivity and systemic glucose utilization in conscious rats. Metabolism 47: 1274-80, 1998

44. Sivitz WI, Walsh SA, Morgan DA, Thomas MJ, and Haynes WG. Effects of leptin on insulin sensitivity in normal rats. Endocrinology 138: 3395-3401, 1997.

45. Srere PA. Citrate synthase. In: Methods in Enzymology. New York: Academic, 1969, p. 3-5.

46. Stephens JM and Pekala PH. Transcriptional repression of the GLUT4 and C/EBP genes in 3T3-L1 adipocytes by tumor necrosis factor-alpha. J Biol Chem 266: 21839-21845, 1991.

47. Stephens TW, Basinski M, Bristow PK, Bue-Valleskey JM, Burgett SG, Craft L, Hale J, Hoffman J, Hsiung HM, Kriauciunas A, MacKellar W, Rosteck PR, Schoner B, Smith D, Tinsely FC, Zhang X-Y, and Heiman M. The role of neuropeptide $\mathrm{Y}$ in the antiobesity action of the obese gene product. Nature 377: 530-532, 1995.

48. Storlien LH, James DE, Burleigh KM, Chisolm DJ, and Kraegen EW. Fat feeding causes widespread in vivo insulin resistance, decreased energy expenditure, and obesity in rats. Am J Physiol Endocrinol Metab 251: E576-E583, 1986.

49. Storlien LH, Jenkins AB, Chisolm DJ, Pascoe WS, Khouri S, and Kraegen EW. Influence of dietary fat composition on development of insulin resistance in rats. Relationship to muscle 
triglyceride and omega-3 fatty acids in muscle phospholipid. Diabetes 40: 280-289, 1991.

50. Takahashi N, Waelput W, and Guisez Y. Leptin is an endogenous protective protein against the toxicity exerted by tumor necrosis factor. J Exp Med 189: 207-212, 1999.

51. Tartaglia L, Dembski M, Weng X, Deng G, Culpepper J, Devos R, Richards GJ, Campfield LA, Clark FT, Deeds J, Muir C, Sanker S, Moriarty A, Moore KJ, Smutko JS, Mays GG, Woolf EA, Monrow CA, and Tepper RI. Identification and expression cloning of a leptin receptor, OB-R. Cell 83: 12631271, 1995.

52. Touster O, Aronson NN, Dulaney JT, and Hendrickson H. Isolation of rat liver plasma membranes. Use of nucleotide pyrophosphatase and phosphodiesterase I as marker enzymes. J Cell Biol 47: 604-618, 1970.

53. Towbin H, Staehelin T, and Gordon J. Electrophoretic transfer of proteins from polyacrylamide gels to nitrocellulose sheets: procedure and some applications. Proc Natl Acad Sci USA 76: 4350-4354, 1979.

54. Turcotte LP, Swenberger JR, Tucker MZ, and Yee AJ. Training-induced elevation in $\mathrm{FABP}_{\mathrm{pm}}$ is associated with increased palmitate use in contracting muscle. J Appl Physiol 87: 285-293, 1999.
55. Uyeda $\mathbf{K}$ and Racker E. Regulatory mechanisms in carbohydrate metabolism. VII. Hexokinase and phosphofructokinase. J Biol Chem 240: 4682-4688, 1965.

56. Wang JL, Chinookoswong N, Scully S, Qi M, and Shi ZQ. Differential effects of leptin in regulation of tissue glucose utilization in vivo. Endocrinology 140: 2117-2124, 1999.

57. Wang MY, Zhou YT, Newgard CB, and Unger RH. A novel leptin receptor isoform in rat. FEBS Lett 392: 87-90, 1996.

58. Wilkes JJ, Bonen A, and Bell RC. A modified high-fat diet induces insulin resistance in rat skeletal muscle but not adipocytes. Am J Physiol Endocrinol Metab 275: E679-E686, 1998.

59. Wu-Peng XS, Chua J, SC, Okada N, Liu S-M, Nicolson M, and Leibel RL. Phenotype of the obese Koletsky (f) rat due to Tyr763stop mutation in the extracellular domain of the leptin receptor (Lepr). Diabetes 46: 513-518, 1997.

60. Yaspelkis BB III, Ansari L, Ramey EA, and Loy SF. Chronic leptin administration increases insulin-stimulated skeletal muscle glucose uptake and transport. Metabolism 48: 671-676, 1999.

61. Yaspelkis BB III, Castle AL, Farrar RP, and Ivy JL. Contraction-induced intracellular signals and their relationship to muscle GLUT-4 concentration. Am J Physiol Endocrinol Metab 272: E118-E125, 1997.

62. Zhang Y, Proenca R, Maffei M, Barone M, Leopold L, and Friedman JM. Positional cloning of the mouse obese gene and its human homologue. Nature 372: 425-432, 1994.

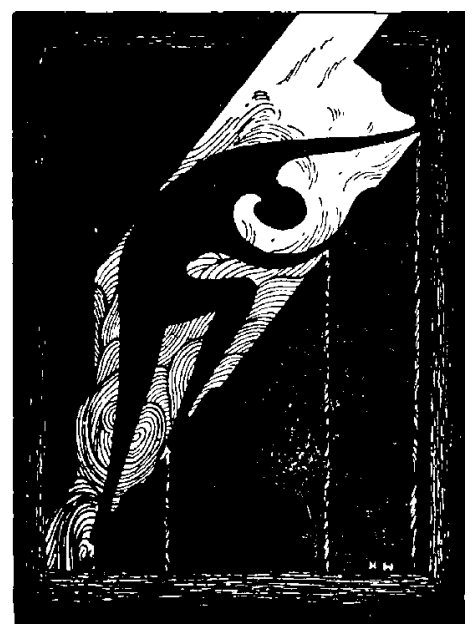

